\title{
Determinants of exhaustion of informal caregivers in homecare. Structural equation analysis of data of a multicenter study
}

\author{
Ralf Suhr ${ }^{1}$, Johannes Habel ${ }^{2}$, Jana Herzberg ${ }^{3}$ and Nils A Lahmann ${ }^{3 *}$ \\ ${ }^{1}$ Centre for Quality in Care Foundation, Berlin, Germany \\ ${ }^{2}$ C.T. Bauer College of Business, University of Houston, Houston, Texas, United States \\ ${ }^{3}$ Charité - Universitätsmedizin Berlin, corporate member of Freie Universität Berlin, Humboldt-Universität zu Berlin, and Berlin Institute of Health, Institute of \\ Health and Nursing Science, Berlin, Germany
}

\begin{abstract}
Background/Aims: Family members, who are often involved in providing home care, are often referred to as informal caregivers. The aim of our study is to analyze how their involvement in caregiving is connected to exhaustion and how this is influenced by caregiving training, social integration and appreciation controlled for social and demographic determinants.

Methods: Across Germany, a multi-center study with randomly selected home care services was conducted in 2015. Questionnaires were based on the ARR inventory and handed out to informal caregivers and home care nurses separately. 223 complementary datasets could be analyzed for our purpose. A structural equation model was used to analyze the data.

Results: First, objective involvement in caregiving increases subjective involvement $(\beta=0.161, \mathrm{p}<0.01)$, which in turn increases exhaustion $(\beta=0.231$, $\mathrm{p}<0.001)$. Second, the interactive effects between objective involvement and both caregiving training $(\beta=-0.184, p<0.001)$ and social integration $(\beta=-0.094$, $p<0.05)$ on subjective involvement in caregiving are statistically significantly negative. Similarly, the interactive effect on exhaustion between subjective involvement in caregiving and appreciation is negative $(\beta=-0.126, \mathrm{p}<0.01)$.

Conclusion: If a caregiving relative has received training or is socially integrated, the effect of objective involvement on subjective involvement in caregiving is less pronounced. Further, the effect of subjective involvement in caregiving on exhaustion is less pronounced if an informal caregiver feels appreciated. Therefore, caregiving training and appreciation are important to moderate exhaustion in informal caregivers.
\end{abstract}

\section{Introduction}

Across Europe, people live longer and the number of people aged $65+$ is expected to rise [1]. The increasing prevalence of old age and chronic diseases poses numerous challenges to the health systems of the individual countries, but also to the patients themselves and, increasingly, to their social networks. Studies have shown that family members, referred to as informal caregivers, are often involved in providing home care, and thus represent an important resource for the health care system [2,3]. In Germany, it is estimated that the largest proportion of those in need of care (70.9\%) living in their own household are cared for by relatives, with the number of people cared for at home rising steadily [4]. This corresponds to findings that the majority of the population in Germany would like to be cared for by relatives in their own homes in case of care dependency [3]. Therefore, informal caregivers in Germany and, also in other countries of the European Union, are regarded as the "largest care service" [3]. Among political decision makers and health care stakeholders there is a growing awareness about the role and importance of informal caregivers. They are defined as someone "who provides help to someone with a chronic illness, disability or other long-term health or support need, outside a professional or formal framework"[5]. Coping with chronic diseases and care dependency is highly complex as physical, psychological, social and economic components affect the health care process [6].
Further, this process is highly dynamic and requires the informal caregivers' ability to react to continuous adjustments according to the care recipients' specific needs [7].

Studies on the burdens for caregiving relatives and on the development and effective application of family-oriented support have expanded in care and intervention research in recent years. When caregiving continues over a long period, caregivers could experience distress and burnout, which results in psychological morbidity, depression, and increased frequency of illnesses [8,9]. Exhaustion disorder is considered as the most valid clinical equivalent of burnout [10]. High reported levels of emotional exhaustion and reduced personal accomplishment established the relevance of the burnout construct for informal caregivers [11].

Informal caregivers who work in addition to caring for a relative - so-called working carers - experience an increased level of stress

*Correspondence to: Nils A Lahmann, Charité - Universitätsmedizin Berlin, corporate member of Freie Universität Berlin, Humboldt-Universität zu Berlin, and Berlin Institute of Health, Geriatrics Research Group, Berlin, Germany

Received: December 11, 2020; Accepted: December 22, 2020; Published: December 27, 2020 
[12]. In addition, family demands, such as caring for children and for one's own couple relationship, can be perceived as challenging [13]. In general, informal caregivers show lower levels of quality of life (QoL) and it was demonstrated that greater burden for informal caregivers is connected to lower QoL [14]. It also worsened in relation with lesser experience of informal caregivers, with lack of financial remuneration and with unemployment [14]. This means that also a family's economic status is a determinant to burden increase.

However, different groups of informal caregivers evaluate specific care situations differently. "Many factors influence the impact of the caregiving experience such as gender, relationship to the patient, culture, and personal characteristics"[15]. Studies have shown that specific other determinants like availability and perception of social support, the acceptance of the role as a caregiver or the motives for taking on care may have a strong influence on the individual perception of the caregiving situation [16]. In addition to the extent of motivation, the differentiation of one's own needs from those of care recipients also influences the perception of the perceived stress [17]. Three basic psychological needs have been identified for informal caregivers: the need for competence, autonomy and social inclusion, because this affects the intrinsic motivation for providing informal care [18]. The following specific areas of caregivers' needs can be distinguished: First, the need for general and personal information about the disease; second, the need for support in coping with the disease and the care; third, the need for social contacts and support; and fourth, the need for medical care for themselves and relief of the care situation [19]. Furthermore it is important for informal caregivers to feel appreciated and recognized of their care work [20].

The aim of our study is to analyze how the involvement of relatives in caregiving (informal caregivers) is connected to exhaustion and how it is influenced by training, social integration and appreciation controlled for social and demographic determinants. The rationale for the influencing variables is the following:

- Being trained strengthens the care competences and skills of informal caregivers and consequently, a given objective level of involvement in caregiving may subjectively appear less pronounced thus leading to less exhaustion.

- Being socially integrated alleviates informal caregivers' perception of their objective involvement in caregiving and consequently, a given objective level of involvement in caregiving may subjectively appear less pronounced thus leading to less exhaustion.

- Receiving appreciation alleviates informal caregivers' perception of their objective involvement in caregiving and consequently, a given objective level of involvement in caregiving may subjectively appear less pronounced thus leading to less exhaustion.

\section{Material and methods}

The multi-center point prevalence study was carried out 2015 as a cross-sectional survey throughout Germany in home care services in all 16 federal German states. The stratified random sampling was conducted in two stages. On the first stage 9 nursing services were included into the study. The selected care services were contacted and asked, whether they would like to participate in the study. This procedure was continued until the target number of 9 nursing services per federal state had been reached. As an incentive, all participating institutions received a certificate confirming their involvement in a scientific study and an expense allowance of 100 euros. On the second stage 9 clients and their next of kin per nursing service were randomly selected and interviewed.

\section{Study participations}

For the inclusion of the institutions, the only criterion was a minimum of at least 10 clients. The inclusion criteria for the clients were the oral informed consent either by themselves or their next of kin and the minimum age of 18 years. The study was approved by the ethics commission of the Medical Association of Berlin (Eth-873-262/00). We used complementary information from care services and caregiving relatives. To collect data, one questionnaire was handed out to carerecipients by the care services and another one to their caregiving relatives. Both questionnaires were pseudonymized with the same ID so that the information of both questionnaires could be merged, and one combined dataset could be analyzed for this study.

\section{Measures and variables}

Information about the objective involvement in care was given by the home care service, using a five-point scale. Information about its labelling can be found in the legend of Table 1. The dichotomous question (yes/no) about whether or not the informal care giver are trained with respect to caregiving was also given by the home care service staff. Information that was received from the relative / informal care giver was based on items from the "ARR", a validated inventory about the risks an resources of informal care givers (21). Again, Information about all labelling can be found in the legend of Table 1.

Apart from our independent variable (objective involvement in caregiving) and our dependent variable (exhaustion), we integrated subjective involvement as a mediating dependent variable and training, social integration and appreciation as moderating variable. We operationalized exhaustion and appreciation by using the sum score of 3 single items, respectively. To confirm our considerations, we calculated the internal consistency of both and considered the Cronbach's $\alpha=0.790$ (0.762) of exhaustion (appreciation) sufficient. For all other variables and controls, we used only one item.

\section{Model specification}

A structural equation model (SEM) (Figure 1) was specified with the following basic idea: We expect several variables (boxes) to be causally interlinked (arrows). Hereby, an arrow that links two boxes denote an expected causal effect of the first on the second variable. An arrow that links a variable to another arrow denotes an expected moderation effect, or, in other words, and interactive effect between two variables on a third variable $[22,23]$.

Following this logic, the path model in Figure 1 is depicted as a causal chain linking informal caregivers' objective involvement in caregiving via their subjective involvement to the feeling of exhaustion. More specifically, we expected the informal caregivers' objective involvement in the care to impact how they perceived their subjective involvement. Moreover, we expected this subjective involvement in caregiving to increase exhaustion. We also included three moderators that are expected to determine the strength of these interrelations. Specifically, we expected objective involvement in caregiving to have a less pronounced influence on subjective involvement in case caregiving relatives have received training and when they are socially integrated. We furthermore expected subjective involvement to have a less pronounced influence on exhaustion in case caregiving relatives feel appreciated for their involvement in the care. To take into account potentially intervening factors, we also included a set of control variables (e.g. demographics of the care recipient and caregiver) that potentially influence informal caregivers' subjective involvement in caregiving as well as exhaustion. 
Table 1: Measurement scales

\begin{tabular}{|c|c|c|c|}
\hline Construct & Measurement Source & Item & Role \\
\hline Objective involvement in caregiving & Care service & - How frequently are other people involved in caregiving? ${ }^{\mathrm{a}}$ & Independent variable \\
\hline Subjective involvement in caregiving & Relative & - How strongly do you feel involved in domestic caregiving? & Mediating dependent variable \\
\hline $\begin{array}{l}\text { Exhaustion } \\
\text { (Cronbach's } \alpha=.790 \text { ) }\end{array}$ & Relative & $\begin{array}{l}\text { - I often feel physically exhausted } \\
\text { - How would you describe your sleep in the past } 4 \text { weeks? }^{\mathrm{d}} \\
\text { - How would you describe your general health situation? }{ }^{\mathrm{d}}\end{array}$ & Dependent variable \\
\hline Caregiving training & Care service & $\begin{array}{l}\text { - Are these people [i.e., people who are involved in caregiving] trained with } \\
\text { respect to caregiving for the client? }\end{array}$ & Moderating independent variable \\
\hline Social integration & Relative & - I regularly meet a group of people..$^{c}$ & Moderating independent variable \\
\hline $\begin{array}{l}\text { Appreciation } \\
\text { (Cronbach's } \alpha=0.762)\end{array}$ & Relative & $\begin{array}{l}\text { - I feel appreciated as a caregiving relative. }{ }^{\mathrm{c}} \\
\text { - My caregiving is appreciated by other people. }{ }^{\mathrm{c}} \\
\text { - I experience gratitude from my relative for my support. }{ }^{\mathrm{c}}\end{array}$ & Moderating independent variable \\
\hline Care recipient's age & Care service & - Year of birth (was then re-calculated to age) & Control \\
\hline Care recipient's gender & Care service & - Gender & Control \\
\hline Care recipient's Barthel index & Care service & - See Mahoney and Barthel (1965) & Control \\
\hline Care giver's age & Relative & - Age & Control \\
\hline Care giver's gender & Relative & - Gender & Control \\
\hline Care giver's job situation & Relative & - Working status ${ }^{\mathrm{f}}$ & \\
\hline Care giver's living situation & Relative & - Do you live in the same household as the care recipient? & Control \\
\hline Care giver's caregiving experience & Care service & $\begin{array}{l}\text { - How low have these people [i.e., people who are involved in caregiving] been } \\
\text { involved in caregiving? }\end{array}$ & Control \\
\hline Care service frequency & Care service & - How often does the care service visit the care recipient? ${ }^{\mathrm{h}}$ & Control \\
\hline
\end{tabular}

a Five-point scale, labeled 1 = "less than three times per week," 2 = "every two days," 3 = "once per day," 4 = "twice to three times per day," 5 = "all day"

${ }^{\mathrm{b}}$ Ten-point scale, anchored $1=$ "I do not feel involved at all" and 10= "I feel involved very strongly"

" Four-point scale, anchored $1=$ "do not agree" and 4= "fully agree"

"Four-point scale, labeled 1= "very good," 2= "rather good," $3=$ "rather bad," 4= "very bad"

e Dummy variable

${ }^{\mathrm{f}}$ Three-point scale, labeled 0 = "not employed," $1=$ "part-time employed," 2 = "full-time employed"

gh Interval scale, labeled 0 = "24-hour care," 1 = "daily," 2 = "weekly," 3 = "every two weeks," 4 = "once per month"

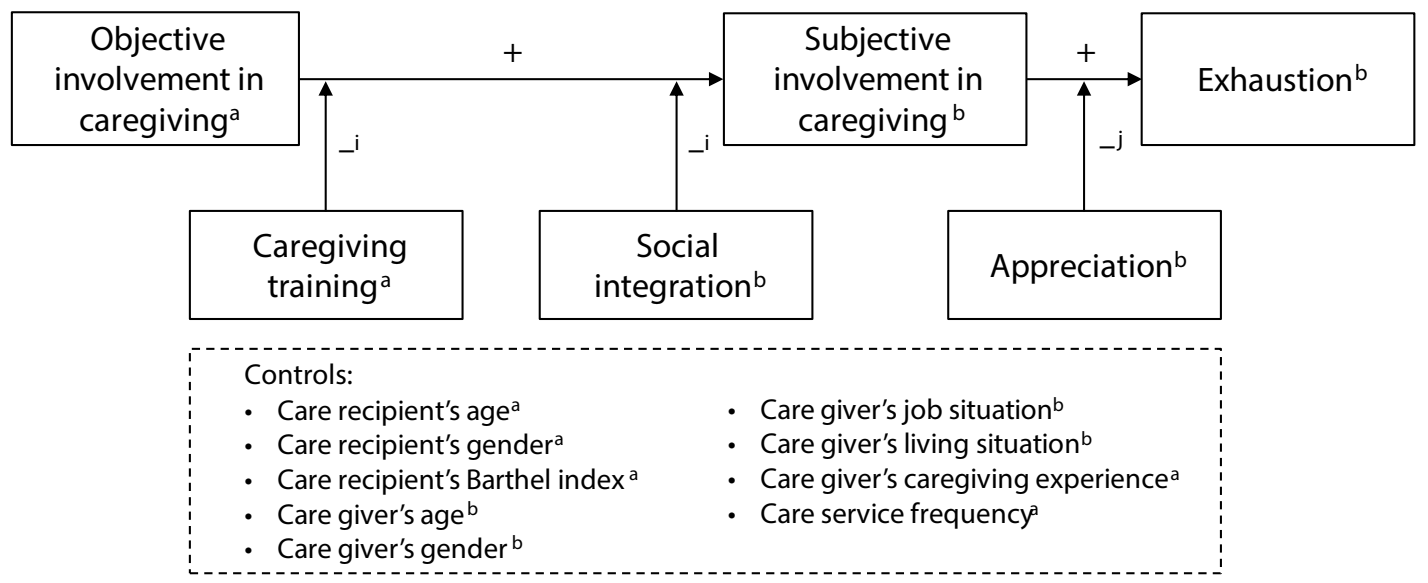

${ }^{a}$ Data retrieved from home care service, ${ }^{b}$ data retrieved from informal care giver/relative

${ }^{i}$ Pertains to the expected interactive effect of the respective variable and objective involvement in caregiving. Thus, we expect that the respective variable weakens the positive effect of objective involvement in caregiving on subjective involvement in caregiving.

j Pertains to the expected interactive effect of the appreciation and subjective involvement in caregiving. Thus, we expect that appreciation weakens the positive effect of subjective involvement in caregiving on exhaustion.

Figure 1. Structural equation model for informal caregiver's exahustion 


\section{Statistical analysis}

To estimate the structural equation model depicted in figure 1, we translated the model into two regression equations that explain our dependent variables, i.e. subjective involvement in caregiving and exhaustion. Specifically, each dependent variable is explained through a linear combination of all variables that are expected to be causal predictors of these dependent variables. These linear combinations also include our moderating variables as well as multiplications between predicting variables and moderating variables [23]. Thus, the two regression equations are specified in Box 1 :

\section{Box 1 regression equations}

$$
\begin{aligned}
& \text { Subjective involvement in caregiving } \\
& \begin{aligned}
=\alpha_{1} & +\beta_{11}{ }^{*} \text { objective involvement in caregiving } \\
& +\beta_{12}{ }^{*} \text { caregiving training } \\
& +\beta_{13}{ }^{*} \text { social integration } \\
& +\beta_{14}{ }^{*} \text { objective involvement in caregiving }{ }^{*} \text { caregiving training } \\
& +\beta_{15}{ }^{*} \text { objective involvement in caregiving }{ }^{*} \text { social integration } \\
& +\beta_{1 n}{ }^{*} \text { controls }+\varepsilon_{1}
\end{aligned}
\end{aligned}
$$

\section{Exhaustion}

$=\alpha_{2}+\beta_{21}{ }^{*}$ subjective involvement in caregiving

$$
+\beta_{22}^{*} \text { appreciation }
$$

$+\beta_{23}{ }^{*}$ subjective involvement in caregiving ${ }^{*}$ appreciation

$$
+\beta_{2 \mathrm{n}}{ }^{*} \text { controls }+\varepsilon_{2}
$$

where $\alpha$ is the intercept, $\beta$ is the regression coefficient and $\varepsilon$ is the error term.

To estimate this model, it is important to note that our data is of a hierarchical structure, with caregivers and care recipients being nested in care services. Thus, the observations in the dataset are not independent from one another, which is a basic assumption of the ordinary least squares estimator. When this assumption is violated, regression coefficients may be biased and a multilevel estimation approach may be required [24]. To assess whether this is true for our data, we inspected interclass correlation coefficients (ICC), which indicate the proportion of variance that resides between the groups, i.e., between care services. In our study, the ICC for subjective involvement in caregiving is .07 and thus exceeds the recommended threshold of .05 [24]. Thus, we resorted to a multilevel estimator, or, more specifically, to a random intercept model [24]. Before running the model, we centered all predictor variables on their grand means to reduce multicollinearity issues and facilitate the interpretation of interaction effects [22]. We then estimated the model using the statistical software package Mplus 7 [25].

\section{Sample description}

We received 880 completed care recipient questionnaires from the home care services and 751 completed questionnaires from informal caregivers. The intersection of both datasets comprised 652 combined patient informal caregiver datasets. For this study, we used those 223 datasets that did not have any missing values, as we needed a large number of variables to run our SEM Model.

\section{Results}

To detect possible systematic bias due to the large amount of excluded cases, we compared included and excluded cases regarding the SEM variables in Table 2.

No significant statistical differences between included and excluded case could be found, apart from the Barthel score which was lower (55.88) in the included group than in the excluded group (63.83).

The mean age of the caregivers (care recipients) was 62.3 (79.4); 66\% (61\%) of the caregivers (care recipients) were female. Table 3 reports descriptive statistics and correlations for our main variables. Objective and subjective involvement in caregiving were $3.44 \pm 1.49$ and 6.65 \pm 2.6 , respectively. These involvements are statistically significantly correlated with exhaustion $(\mathrm{r}$

\begin{tabular}{|c|c|c|c|c|c|c|c|}
\hline \multirow[b]{2}{*}{ Construct } & \multicolumn{3}{|c|}{ Excluded Observations } & \multicolumn{3}{|c|}{ Included Observations } & \multirow{2}{*}{$\begin{array}{l}p \text {-value from t-test for } \\
\text { mean difference }\end{array}$} \\
\hline & M & SD & $\mathbf{N}$ & M & SD & $\mathbf{N}$ & \\
\hline Objective involvement in caregiving & 3.16 & 1.52 & 175 & 3.44 & 1.49 & 223 & 0.062 \\
\hline Subjective involvement in caregiving & 6.42 & 2.86 & 177 & 6.65 & 2.60 & 223 & 0.412 \\
\hline Exhaustion & 2.34 & 0.66 & 198 & 2.28 & 0.67 & 216 & 0.377 \\
\hline Caregiving training & 0.33 & 0.47 & 219 & .37 & 0.48 & 223 & 0.394 \\
\hline Social integration & 1.82 & 0.87 & 194 & 2.03 & 0.80 & 223 & 0.071 \\
\hline Appreciation & 3.04 & 1.12 & 186 & 3.11 & 1.22 & 223 & 0.413 \\
\hline Care recipient's age & 77.64 & 13.48 & 429 & 79.41 & 10.89 & 223 & 0.092 \\
\hline Care recipient's gender & 1.61 & 0.49 & 425 & 1.61 & 0.49 & 223 & 0.991 \\
\hline Care recipient's Barthel index & 66.85 & 29.58 & 275 & 53.88 & 30.27 & 223 & $<0.001$ \\
\hline Care giver's age & 62.70 & 14.69 & 201 & 62.33 & 14.26 & 223 & 0.793 \\
\hline Care giver's gender & 1.66 & 0.47 & 218 & 1.66 & 0.48 & 223 & 0.976 \\
\hline Care giver's job situation & 0.56 & 0.83 & 195 & 0.57 & 0.81 & 223 & 0.940 \\
\hline Care giver's living situation & 0.52 & 0.50 & 217 & 0.56 & 0.50 & 223 & 0.351 \\
\hline Care giver's caregiving experience & 3.74 & 0.67 & 226 & 3.78 & 0.61 & 223 & 0.493 \\
\hline Care service frequency & 1.16 & 0.47 & 427 & 1.23 & 0.47 & 223 & 0.064 \\
\hline
\end{tabular}
subjective involvement, exhaustion $=0.40, p<0.001)$. $=0.20, p=0.004 ; \mathrm{r}$

Table 4 depicts the results of our model estimation. First, objective involvement increases subjective involvement $(\beta=0.161, p=0.006)$, which in turn increases exhaustion $(\beta=0.231, p<0.001)$. Second, the interactive effects between objective involvement in caregiving and both caregiving training $(\beta=-0.184, p<0.001)$ and social integration

Table 2: Comparison of included and excluded observations (test for Selection Bias)

$\mathrm{M}=$ mean, $\mathrm{SD}=$ standard deviation, $\mathrm{N}=$ sample size . 
Table 3: Descriptive statistics and correlations

\begin{tabular}{|c|c|c|c|c|c|c|c|}
\hline Variable & $\mathbf{M}$ & SD & $\mathbf{V 1}$ & $\mathbf{V} 2$ & $\mathbf{V 3}$ & $\mathbf{V 4}$ & $\mathbf{V 5}$ \\
\hline V1: Objective involvement in caregiving & 3.44 & 1.49 & & & & & \\
\hline V2: Subjective involvement in caregiving & 6.65 & 2.6 & $0.39 * * * \quad(p<.001)$ & & & & \\
\hline V3: Exhaustion & 2.28 & 0.67 & $0.20 * *(p=0.004)$ & $0.4^{* * *}(p<0.001)$ & & & \\
\hline V4: Caregiving training & $-^{\mathrm{a}}$ & $-^{\mathrm{a}}$ & $0.1(p=0.134)$ & $0.16^{*}(p=0.018)$ & $0.02(p=0.736)$ & & \\
\hline V5: Social integration & 2.03 & 1.22 & $-0.15^{*}(p=0.030)$ & $-0.24 * * *(p<0.001)$ & $-0.29 * * *(p<0.001)$ & $-0.01(p=0.889)$ & \\
\hline V6: Appreciation & 3.11 & 0.8 & $-0.07(p=0.276)$ & $-0.20 * *(p=0.003)$ & $-0.22 * *(p=0.001)$ & $0.08(p=0.255)$ & $0.27 * * *(p<0.001)$ \\
\hline
\end{tabular}

n.s. not significant: $p>0.05, * p<0.05, * * p<0.01, * * * p<0.001$ (two-tailed). ${ }^{a}$ Dummy variable.

Table 4: Results of the model estimation

\begin{tabular}{|c|c|c|c|}
\hline Path & & Estimated Coefficient & $p$-value \\
\hline \multicolumn{4}{|l|}{ Main Links } \\
\hline Objective involvement in caregiving & $\rightarrow$ subjective involvement in caregiving & $0.16^{* *}$ & 0.006 \\
\hline Subjective involvement in caregiving & $\rightarrow$ exhaustion & $0.23 * * *$ & 0.001 \\
\hline \multicolumn{4}{|l|}{ Main Effects of Moderators } \\
\hline Caregiving training & / subjective involvement in caregiving & $0.1^{*}$ & 0.032 \\
\hline Social integration & / subjective involvement in caregiving & $-0.18 * * *$ & $<0.001$ \\
\hline Appreciation & $\rightarrow$ exhaustion & $-0.11^{\text {n.s. }}$ & 0.057 \\
\hline \multicolumn{4}{|l|}{ Interaction Effects } \\
\hline Objective involvement in caregiving $\times$ caregiving training & $\rightarrow$ subjective involvement in caregiving & $-0.18 * * *$ & 0.001 \\
\hline Objective involvement in caregiving $\times$ social integration & $\rightarrow$ subjective involvement in caregiving & $-0.09 *$ & 0.040 \\
\hline Subjective involvement in caregiving $\times$ appreciation & $\rightarrow$ exhaustion & $-0.13 *$ & 0.012 \\
\hline \multicolumn{4}{|l|}{ Controlled Path } \\
\hline Objective involvement in caregiving & $\rightarrow$ exhaustion & $-0.11^{\text {n.s. }}$ & 0.063 \\
\hline Caregiving training & / exhaustion & $-0.04^{\text {n.s. }}$ & 0.273 \\
\hline Social integration & / exhaustion & $-0.17 * *$ & 0.004 \\
\hline Appreciation & $\rightarrow$ subjective involvement in caregiving & $-0.13^{*}$ & 0.029 \\
\hline \multicolumn{4}{|l|}{ Control Variables } \\
\hline Care recipient's age & $\rightarrow$ subjective involvement in caregiving & $0.01^{\text {n.s. }}$ & 0.427 \\
\hline Care recipient's gender & $\rightarrow$ subjective involvement in caregiving & $0.10^{\text {n.s. }}$ & 0.057 \\
\hline Care recipient's Barthel index & $\rightarrow$ subjective involvement in caregiving & $-0.16^{*}$ & 0.009 \\
\hline Care giver's age & $\rightarrow$ subjective involvement in caregiving & $0.11^{\text {n.s. }}$ & 0.117 \\
\hline Care giver's gender & $\rightarrow$ subjective involvement in caregiving & $-0.02^{\text {n.s. }}$ & 0.382 \\
\hline Care giver's job situation & $\rightarrow$ subjective involvement in caregiving & $0.03^{\text {n.s. }}$ & 0.344 \\
\hline Care giver's living situation & $\rightarrow$ subjective involvement in caregiving & $0.24 * * *$ & 0.001 \\
\hline Care giver's care duration & $\rightarrow$ subjective involvement in caregiving & $-0.03^{\text {n.s. }}$ & 0.301 \\
\hline Care service frequency & $\rightarrow$ subjective involvement in caregiving & $-0.01^{\text {n.s. }}$ & 0.413 \\
\hline Care recipient's age & $\rightarrow$ exhaustion & $0.03^{\text {n.s. }}$ & 0.242 \\
\hline Care recipient's gender & $\rightarrow$ exhaustion & $0.03^{\text {n.s. }}$ & 0.315 \\
\hline Care recipient's Barthel index & $\rightarrow$ exhaustion & $-0.17 * *$ & 0.012 \\
\hline Care giver's age & $\rightarrow$ exhaustion & $0.22 * *$ & 0.005 \\
\hline Care giver's gender & $\rightarrow$ exhaustion & $0.07^{\text {n.s. }}$ & 0.125 \\
\hline Care giver's job situation & $\rightarrow$ exhaustion & -0.07 & 0.178 \\
\hline Care giver's living situation & $\rightarrow$ exhaustion & $0.07^{\text {n.s. }}$ & 0.172 \\
\hline Care giver's caregiving experience & $\rightarrow$ exhaustion & $-0.01^{\text {n.s. }}$ & 0.437 \\
\hline Care service frequency & $\rightarrow$ exhaustion & $-0.02^{\text {n.s. }}$ & 0.311 \\
\hline \multicolumn{4}{|l|}{ Model Fit } \\
\hline $\mathrm{R}^{2}$ for subjective involvement & & $0.37 * * *$ & $<0.001$ \\
\hline $\mathrm{R}^{2}$ for exhaustion & & $0.33 * * *$ & $<0.001$ \\
\hline Comparative Fit Index (CFI) & & 0.99 & \\
\hline Tucker-Lewis Index (TLI) & & 0.98 & \\
\hline Root Mean Square Error Of Approximation (RMSEA) & & 0.02 & \\
\hline Standardized Root Mean Square Residual (SRMR) & & 0.01 & \\
\hline$\chi^{2}$ (d.f.) & & $3.19(3)$ & \\
\hline \multicolumn{4}{|l|}{ Sample Size } \\
\hline Between clusters (i.e., care services) & & 80 & \\
\hline Within observations (i.e., care giver-care recipient dyads) & & 22 & \\
\hline
\end{tabular}

Within observations (i.e., care giver-care recipient dyads)

n.s. not significant: $p>.05, * p<.05, * * p<.01, * * * p<.001$ (one-tailed). We report standardized coefficients. 
( $\beta=-0.094, p=0.04)$ on subjective involvement in caregiving are statistically significantly negative. Similarly, the interactive effect between subjective involvement in caregiving and appreciation on exhaustion is significantly negative $(\beta=-0.126, p=0.012)$.

To facilitate interpretation of these moderation effects, Figure 2 presents interaction plots that illustrate the effects of predicting variables (i.e., objective involvement and subjective involvement in caregiving) on outcome variables (i.e., subjective involvement in caregiving, exhaustion) at low and high levels of the moderating variables (i.e., caregiving training, social integration, appreciation). Referring to the above described methodology, Table 4 reports the corresponding simple slopes, i.e. the slopes of the effect lines depicted in Figure 2 [22, 23]. Accordingly, the adverse effects of caregiving are weakened if a caregiver received training, is socially integrated, or feels appreciated.

Lastly, Table 5 also reports the indirect effect of objective involvement in caregiving via subjective involvement in caregiving on exhaustion. As it can be seen, if relatives received caregiving training, are socially integrated or feel appreciated, an increase in objective involvement does not significantly alter their exhaustion via subjective involvement. Conversely, if relatives received caregiving training as well as low rate for social integration and appreciation, an increase in objective involvement significantly increases their exhaustion via subjective involvement. Thus, the negative effect of objective involvement in caregiving on exhaustion via subjective involvement in caregiving is fully alleviated if informal caregivers receive training, are socially integrated, and feel appreciated.

\section{Discussion}

Our results are based on complementary information from two measurement sources (informal caregiver/relatives and professional home care service professionals) allowing us to distinguish between objective information from the professionals and from their perceptions and feelings (subjective information) from the informal caregiver/relative. The results were based on a multi-centric design and data were gathered throughout Germany. On average, relatives who are involved more than once a day in providing informal care, their perceived or subjective involvement can be considered high. The level of exhaustion, indicated also by their physical health and sleep patterns, can be considered critical. Statistically significant bivariate associations between involvement and exhaustion remain strong after inclusion of mediators and potential confounding variables. The effect of objective involvement on subjective involvement in caregiving is less pronounced if an informal caregiver has received caregiving training or is socially integrated. The effect of subjective involvement in caregiving on exhaustion is less pronounced if an informal caregiver feels appreciated. The indirect effect of objective involvement or engagement [26] via subjective involvement in caregiving on exhaustion results from the multiplication of the coefficients of the two direct effects [27,28].

With respect to the pattern of effects, three observations seem noteworthy. First, the interactive effect of objective involvement in caregiving and caregiving training on subjective involvement in caregiving is even stronger than the direct effect of objective on subjective involvement in caregiving, as indicated by the higher standardized regression coefficient. This suggests that caregiving

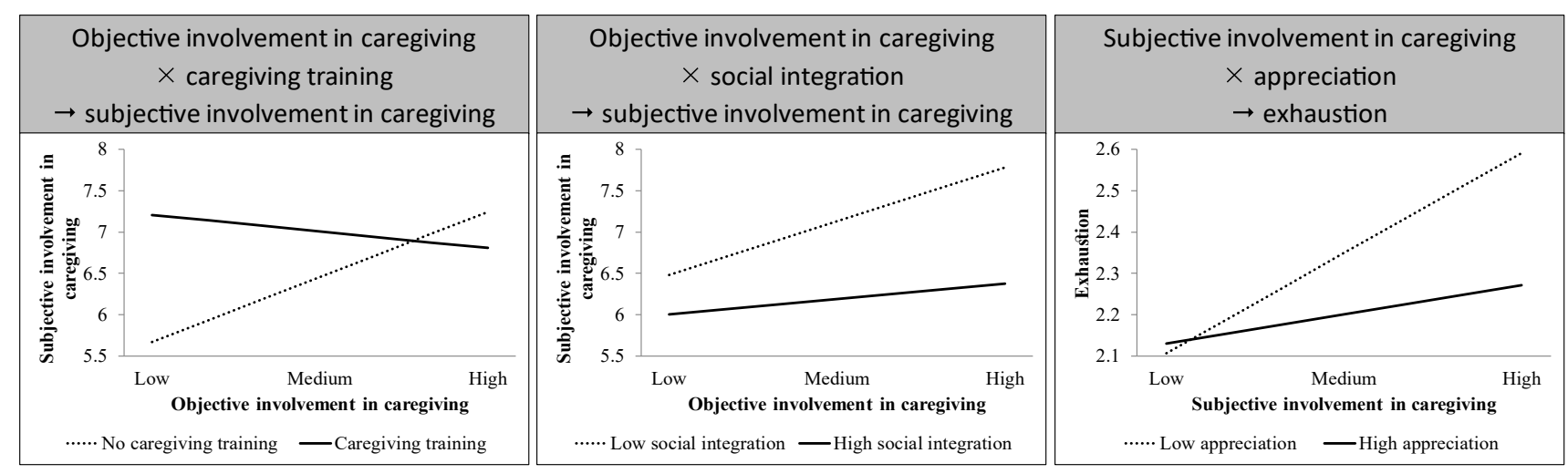

Figure 2. Interaction plots of the moderation effects in the structural equation model

Table 5: Simple slopes and indirect effects

\begin{tabular}{|c|c|c|c|}
\hline Moderator & $\begin{array}{l}\text { Simple Slope: } \\
\text { Objective involvement in caregiving } \\
\rightarrow \text { subjective involvement in caregiving }\end{array}$ & \begin{tabular}{l}
\multicolumn{1}{c}{ Simple Slope: } \\
Subjective involvement in caregiving \\
$\rightarrow$ exhaustion
\end{tabular} & $\begin{array}{l}\quad \text { Indirect Effect: } \\
\text { Objective involvement in caregiving } \\
\rightarrow \text { subjective involvement in caregiving } \\
\rightarrow \text { exhaustion }\end{array}$ \\
\hline \multicolumn{4}{|c|}{ Caregiving training } \\
\hline No & $0.30 * * *(p<0.001)$ & - & $.07 * *(p=0.005)$ \\
\hline Yes & $-0.08^{\text {n.s. }}(p=0.453)$ & - & $-.02^{\text {n.s. }}(p=0.448)$ \\
\hline \multicolumn{4}{|c|}{ Social integration } \\
\hline Low & $0.25 * * *(p=0.001)$ & - & $0.06^{*}(p=0.027)$ \\
\hline High & $0.08^{\text {n.s. }}(p=0.376)$ & - & $0.02^{\text {n.s. }}(p=0.386)$ \\
\hline \multicolumn{4}{|l|}{ Appreciation } \\
\hline Low & - & $0.35^{* * *}(p<0.001)$ & $0.06 *(p=0.041)$ \\
\hline High & - & $0.1^{\text {n.s. }}(p=0.313)$ & $0.02^{\text {n.s. }}(p=0.316)$ \\
\hline
\end{tabular}

n.s. not significant: $p>0.05,{ }^{*} p<0.05,{ }^{*} p<0.01, * * * p<0.001$ (one-tailed). We report standardized coefficients. A low (high) value indicates a value of one standard deviation below (above) the mean value of the variable. 
training fully alleviates the informal caregivers' inference of subjective involvement from objective involvement in caregiving.

Second, however, resulting from its significant main effect, caregiving training leads to an overall higher level of subjective involvement (Figure 2). A potential explanation may be that trained caregivers' expertise on how to provide care leads them to become more aware of their obligations, regardless of their objective involvement. Thus, surprisingly, caregiving training seems to be a double-edged sword: while it lowers the perception of the objective involvement in caregiving, it increases subjective involvement.

Third, the coefficients of the interactive effects suggest that the influence of caregiving training is almost twice as high in reducing caregiving relatives' inference of subjective from objective involvement as that of social integration. This finding may seem surprising at a first glance seeing that relatives' social integration is frequently considered a key remedy against negative psychological effects of caregiving. However, we hold that the finding is plausible: While social integration may mainly divert caregivers from their obligations for a certain period of time, caregiving training should facilitate caregiving by improving individual skills and increasing knowledge stocks and is likely to make caregiving easier.

The results indicate that professionals should pay attention to the needs of informal caregivers and offer support and training in order to reduce the exhaustion of family carers, which may in turn reduce informal caregivers' vulnerability and their risk for mental illness [29]. Further, interventions to support, qualify and accompany informal caregivers promise to mitigate the negative effects of home care. They lead to less pronounced psychosomatic complaints, reduced aggressive behavior and a lower mortality risk for caregivers [30]. Adequate support and relief for informal caregivers improves their general health and well-being and reduces depressive symptoms and family anxiety about care at home [31] Corresponding to other studies, our results indicate, that promoting informal caregiving and support programs can assist informal caregivers to reduce the burden and psycho-emotional distress [32,33]. Since 2005 different training programs, sponsored by the German health insurance agencies have been implemented for informal carers [34]. Meanwhile in 2017, a new national law (PSG II, the second law on the strengthening of nursing care) responded to the continuously growing demand for training courses for family carers and established additional caregiver training programs. Although political decision makers and health care planners have already recognized the importance of informal care, the individual situation and coping behavior of caregivers are often neglected. With the exception of special diseases - e.g. dementia [16], tumor diseases [35] and neurological diseases [36] - support services are often not tailored to the very specific needs of informal caregivers [37] On the other hand, studies have shown that available support services are not made use of to the desired extent, especially psychosocial interventions [38]. This phenomenon occurs in Germany as well as in other European countries [39]. However, training courses for informal caregivers have proven to be effective when the care-receiving relatives are cared for and supported during the course. There are also Stress-management programs supporting and empowering family caregivers to cope more effectively [40]. In summary, the above-mentioned effects of the various interventions illustrate their relevance for maintaining the health of informal caregivers and their willingness to care for their relatives in need of care.

\section{Limitation}

As our study is based on a cross sectional design, we can only show associations and have to be careful to draw causal conclusions. We are aware that the constructions of our main dimensions like subjective / objective involvement, social integration, etc. are only build on very few and somehow untested items, hence the construct may have limitations regarding its stability. The reason for this was that we were aware that answering long questionnaires would have been too complicated for this vulnerable population, which would have caused a lower response, since we only included data when both data sets - the one of the carereceiving relatives and the one of the connected informal caregiver - were available. The number of excluded cases was high because we aimed to include a considerable amount of variables in our model - gathering complete sets of data in such a vulnerable population remains a large challenge, which may cause a mild form of selection bias. However, we could show that the included and the excluded sample were highly comparable. However, the above-described relation between exhaustion and involvement in caregiving entails a high amount of plausibility.

\section{Funding}

The study was funded by the Zentrum für Qualitaet in der Pflege, REF: 2015/003.

\section{Conflict of interest}

We certify that there is no conflict of interest with any financial or other organization regarding the material discussed in the manuscript. Jana Herzberg is a doctoral student, who will use this article for her $\mathrm{PhD}$ thesis.

\section{References}

1. European Commission (2006) The demographic future of Europe - from challenge to opportunity. Brussels: European Commission.

2. Sorrell JM (2007) Caring for the caregivers. J Psychosoc Nurs Ment Health Serv 45 17-20. [Crossref]

3. Bestmann B, Wüstholz E, Verhheyen F (2014) Pflegen: Belastung und sozialer Zusammenhalt ; eine Befragung zur Situation von pflegenden Angehörigen. Hamburg. Wissenschaftliches Institut der Techniker Krankenkasse für Nutzen und Effizienz im Gesundheitswesen.

4. Nowossadeck S, Engstler H, Klaus D (2016) Pflege und Unterstützung durch Angehörige. Berlin: Deutsches Zentrum für Altersfragen.

5. Glendinning C, Tjadens F, Arksey H, Moree M, Moran N, et al. (2009) Care provision within families and its socio-economic impact an care providers: Report for the European Commission DG EMPL Negotiated Procedure VT/2007/114. Utrecht, York: University of York in collaboration with Vilans Centre ofExpertise for Long-Term Care.

6. Schaeffer D, Haslbeck J (2016) Bewältigung chronischer Krankheit. In: Richter M, Hurrelmann K, editors. Soziologie von Gesundheit und Krankheit. Wiesbaden Springer. p. 243-56.

7. Corbin JM, Strauss AL (2010) Weiterleben lernen. Verlauf und Bewältigung chronischer Krankheit 3ed. Bern: Huber.

8. Truzzi A, Valente L, Ulstein I, Engelhardt E, Laks J, et al. (2012) Burnout in familial caregivers of patients with dementia. Braz J Psychiatry 34: 405-412. [Crossref]

9. Hiyoshi-Taniguchi K, Becker CB, Kinoshita A (2018) What Behavioral and Psychological Symptoms of Dementia Affect Caregiver Burnout? Clin Gerontol 41: 249-254. [Crossref]

10. Grossi G, Perski A, Osika W, Savic I (2015) Stress-related exhaustion disorderclinical manifestation of burnout? A review of assessment methods, sleep impairments, cognitive disturbances, and neuro-biological and physiological changes in clinical burnout. Scand J Psychol 56: 626-636. [Crossref]

11. Lee H, Singh J (2010) Appraisals, burnout and outcomes in informal caregiving. Asian Nurs Res 4: 32-44. [Crossref] 
12. Qadir F, Gulzar W, Haqqani S, Khalid A (2013) A pilot study examining the awareness, attitude, and burden of informal caregivers of patients with dementia. Care Manag $J$ 14: 230-240. [Crossref]

13. Brodaty H, Donkin M (2009) Family caregivers of people with dementia. Dialogues Clin Neurosci 11: 217-218. [Crossref]

14. Rodrigues AM, Ferreira PL, Ferre-Grau C (2016) Providing informal home care for pressure ulcer patients: how it affects carers' quality of life and burden. J Clin Nurs 25 : 3026-3035. [Crossref]

15. Etters L, Goodall D, Harrison BE (2008) Caregiver burden among dementia patient caregivers: a review of the literature. J Am Acad Nurse Pract 20: 423-428. [Crossref]

16. Kurz A, Wilz G (2011) Die Belastung pflegender Angehöriger bei Demenz. Entstehungsbedingungen und Interventionsmöglichkeiten. Der Nervenarzt 82: 336342 .

17. Engel S (2008) Angehörigenberatung - Verbesserung der Situation pflegender Angehöriger als ein zentrales Arbeitsfeld der Gerontopsychologie. In: Oswald WD, Gatterer G, Fleischmann UM, editors. Gerontopsychologie Grundlagen und klinische Aspekte zur Psychologie des Alterns. 2. Wien New York: Springer.

18. Deci EL, Ryan RM (2012) Self-determination theory in health care and its relations to motivational interviewing: a few comments. Int J Behav Nutr Phys Act 9: 24. [Crossref]

19. Poll E, Gauggel S (2009) Beratung von pflegenden Angehörigen demenzkranker Patienten. Zeitschrift für Neuropsychologie 20: 31-38.

20. Plöthner M, Schmidt K, de Jong L, Zeidler J, Damm K (2019) Needs and preferences of informal caregivers regarding outpatient care for the elderly: a systematic literature review. BMC geriatrics 19: 82. [Crossref]

21. Budnick A, Kummer K, Blüher S, Dräger D (2012) Pflegende Angehörigeund Gesundheitsförderung - Pilotstudie zur Validität eines deutschsprachigen Assessments zur Erfassung von Ressourcen und Risiken älterer pflegender Angehöriger (ARR). Z Gerontol Geriatr 45: 201-211. [Crossref]

22. Aiken LS, West SG, Reno RR (1991) Multiple regression: Testing and interpreting interactions: Sage.

23. Cohen J, Cohen P, West SG, Aiken LS (2003) Applied multiple regression/correlation analysis for the behavioral sciences.

24. Hox JJ (2010) Multilevel Analysis: Techniques and Application (2nd ed.). New York: Routledge/Taylor \& Francis Group.

25. Muthén LK, Muthén BO (2012) Mplus Version 7 user's guide. Los Angeles: Muthén \& Muthén.

26. Barello S, Castiglioni C, Bonanomi A, Graffigna G (2019) The Caregiving Health Engagement Scale (CHE-s): development and initial validation of a new questionnaire for measuring family caregiver engagement in healthcare. BMC Public Health 9: 1562. [Crossref]
27. Shrout PE, Bolger N (2002) Mediation in experimental and nonexperimental studies new procedures and recommendations. Psychol Methods 7: 422-445. [Crossref]

28. Baron RM, Kenny DA (1986) The moderator-mediator variable distinction in social psychological research: conceptual, strategic, and statistical considerations. J Pers Soc Psychol 51: 1173-1182. [Crossref]

29. Rojahn J (2014) Family caregivers: fellow patients and co-therapists. Aktuelle Urol 45 : 269-273. [Crossref]

30. Northouse L, Williams AL, Given B, McCorkle R (2012) Psychosocial care for family caregivers of patients with cancer. J Clin Oncol 30: 1227-1234. [Crossref]

31. Harding R, List S, Epiphaniou E, Jones H (2012) How can informal caregivers in cancer and palliative care be supported? An updated systematic literature review of interventions and their effectiveness. Palliat Med 26: 7-22. [Crossref]

32. Park S, Park M (2015) Effects of Family Support Programs for Caregivers of People with Dementia - Caregiving Burden, Depression, and Stress: Systematic Review and Meta-analysis. J Korean Acad Nurs 45: 627-640. [Crossref]

33. Metzelthin SF, Verbakel E, Veenstra MY, van Exel J, Ambergen AW, et al. (2017) Positive and negative outcomes of informal caregiving at home and in institutionalised long-term care: a cross-sectional study. BMC Geriatr 17: 232. [Crossref]

34. Schroer-Mollenschott C, Pustmüller B, Sparenberg J, Haotze E (2011) Kompetenzförderung von pflegenden Angehörigen und Patienten. CW Haarfeld GmbH. Berlin: GKV-Spitzenverband.

35. Potter P, Deshields T, Kuhrik M, Kuhrik N, O'Neill J, et al. (2010) An analysis of educational and learning needs of cancer patients and unrelated family caregivers. $J$ Cancer Educ 25: 538-542. [Crossref]

36. Mitchell LA, Hirdes J, Poss JW, Slegers-Boyd C, Caldarelli H, et al. (2015) Informal caregivers of clients with neurological conditions: profiles, patterns and risk factors for distress from a home care prevalence study. BMC Health Serv Res 15: 350. [Crossref]

37. Dixe MdACR, da Conceição Teixeira LF, Areosa TJTCC, Frontini RC, de Jesus Almeida Peralta T, et al. (2019) Needs and skills of informal caregivers to care for a dependent person: a cross-sectional study. BMC Geriatrics 19: 255. [Crossref]

38. Mischke C (2012) Resources and their meaning for caregivers--a gap in research? Health sociological and empirical approach to a hitherto neglected field of research. Pflege 25: 163-174. [Crossref]

39. Brodaty H, Thomson C, Thompson C, Fine M (2005) Why caregivers of people with dementia and memory loss don't use services. Int J Geriatr Psychiatry 20: 537-546. [Crossref]

40. Lewis SL, Miner-Williams D, Novian A, Escamilla MI, Blackwell PH, et al. (2009) A Stress-Busting Program for Family Caregivers. Rehabilitation Nursing 34: 151-159. [Crossref]

Copyright: (C2020 Suhr R. This is an open-access article distributed under the terms of the Creative Commons Attribution License, which permits unrestricted use, distribution, and reproduction in any medium, provided the original author and source are credited. 